\title{
Traumatic aortic arch false aneurysm after blunt chest trauma in a motocross rider
}

\author{
Federico Bizzarri*1, Consalvo Mattia1 ${ }^{1}$, Massimo Ricci ${ }^{1}$, Ilaria Chirichilli1 ${ }^{1}$ \\ Chiara Santo1, David Rose1, Luigi Muzzi1 ${ }^{1}$, Giuseppe Pugliese ${ }^{1}$, \\ Giacomo Frati ${ }^{1}$, Patrizio Sartini ${ }^{1}$, Riccardo Ferrari ${ }^{2}$, Carlo Della Rocca ${ }^{3}$ and \\ Andrea Laghi ${ }^{2}$
}

\author{
Address: ${ }^{1}$ Cardiac Surgery Unit, Department of Heart and Great Vessels "Attilio Reale", University of Rome "Sapienza", Polo Pontino, via F. \\ Faggiana 34, 04100 Latina, Italy, ${ }^{2}$ Department of Radiology, University of Rome "Sapienza", Polo Pontino, via F. Faggiana 34, 04100 Latina, Italy \\ and ${ }^{3}$ Department of Anatomy and Pathology, University of Rome "Sapienza", Polo Pontino, via F. Faggiana 34, 04100 Latina, Italy \\ Email: Federico Bizzarri* - federico.bizzarri@uniroma1.it; Consalvo Mattia - consalvo.mattia@uniroma1.it; \\ Massimo Ricci - punkindoctor@libero.it; Ilaria Chirichilli - chirichilli@inwind.it; Chiara Santo - io_sc@libero.it; \\ David Rose - davidrose@libero.it; Luigi Muzzi - luigimuzzi@hotmail.it; Giuseppe Pugliese - dott.giuseppe@virgilio.it; \\ Giacomo Frati - fraticello@inwind.it; Patrizio Sartini - patrizio.sartini@uniroma1.it; Riccardo Ferrari - riccardo.ferrari@uniroma1.it; Carlo Della \\ Rocca - carlo.dellarocca@uniroma1.it; Andrea Laghi - andrea.laghi@uniroma1.it \\ * Corresponding author
}

Published: I May 2008

Journal of Cardiothoracic Surgery 2008, 3:23 doi:10.1 186/1749-8090-3-23
Received: 29 February 2008

Accepted: I May 2008

This article is available from: http://www.cardiothoracicsurgery.org/content/3/I/23

(c) 2008 Bizzarri et al; licensee BioMed Central Ltd.

This is an Open Access article distributed under the terms of the Creative Commons Attribution License (http://creativecommons.org/licenses/by/2.0), which permits unrestricted use, distribution, and reproduction in any medium, provided the original work is properly cited.

\begin{abstract}
This article details a case report of a traumatic aortic arch false aneurysm after blunt chest trauma. Thoracic aorta false aneurysms are a rare and life-threatening complication of aortic surgery, infection, genetic disorders and trauma.
\end{abstract}

\section{Background}

Thoracic aorta false aneurysms are a rare and life-threatening complication of aortic surgery, infection, genetic disorders and trauma. After trauma approximately 2\% to 5\% of patients with aortic disruption develop a false aneurysm either after non operative treatment or lack of diagnosis [1]. Little is known about the natural history of this complication. However, a perfused false aneurysm may partially clot and organize with a fibrous wall potentially evolving into a saccular or fusiform aneurysm; late enlargement and even rupture may occur. Ninety percent of the false aneurysms involve the aortic isthmus; this probably reflects a sort of protection by the mediastinal periadventitial tissues at this level $[2,3]$. Patients developing chronic pseudoaneurysms show a low rate of associ- ated injuries at the time of trauma [2,3]; in fact, $35 \%$ present no other injuries, and 50\% only one.

\section{Case report}

A 33 year-old male motocross rider came to our attention complaining of back chest pain and cough. He referred a history of chest trauma 4 years ago during a motorbike race. The trauma resulted in an exstensive left shoulder and head injury associated to multiple rib fractures. He spent one month in hospital; he subsequently improved and was discharged in stable conditions. However, he continued to complain of a progressively increasing chest pain. At chest x-ray a left upper mediastinal mass was detected. A 64 multislice CT scan showed the presence of an aortic aneurysm $(4 \mathrm{~cm} \times 4.5 \mathrm{~cm})$ arising from the descending thoracic aorta (Fig 1, 2, 3); the neck was 


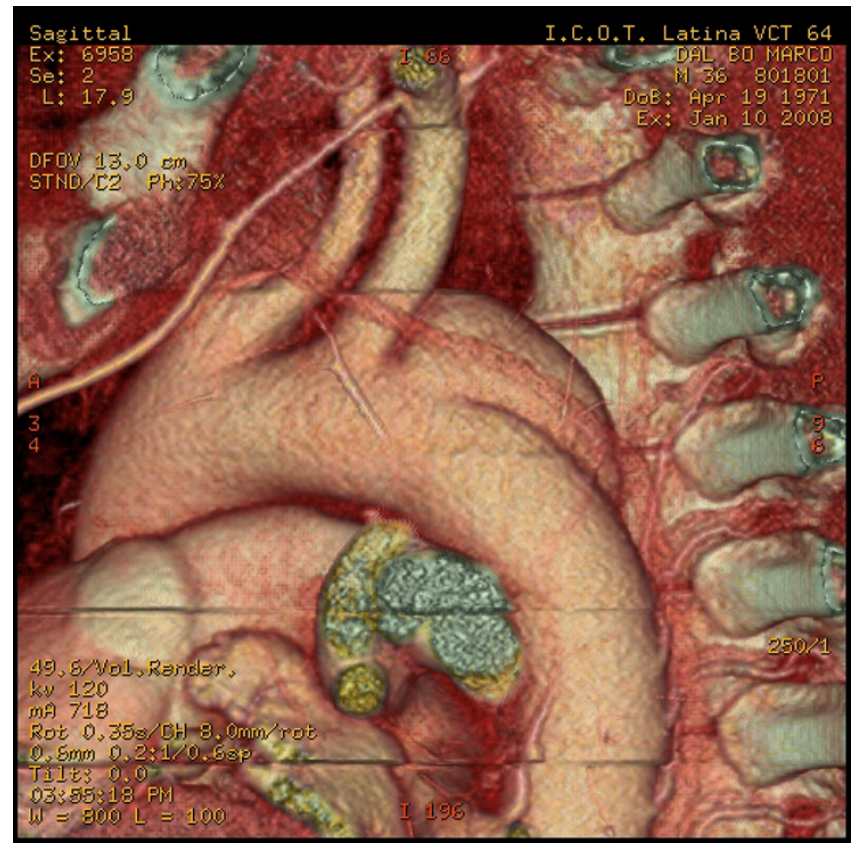

Figure I

pseudoaneurysm and its relationship with surrounding structures.

located immediately after the origin of the left subclavian artery. on the convex aspect of the vessel. CT also showed the presence of a bovine configuration of the aorta. The diagnosis was "post-traumatic false aneurysm" involving

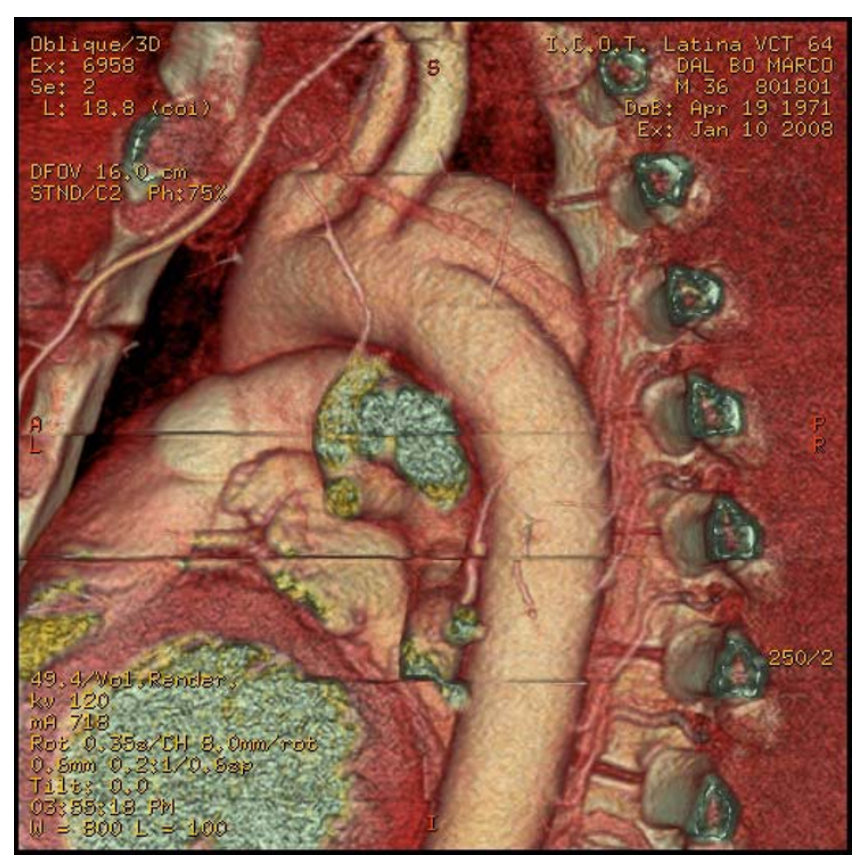

Figure 2

pseudoaneurysm and its relationship with vertebral spine.

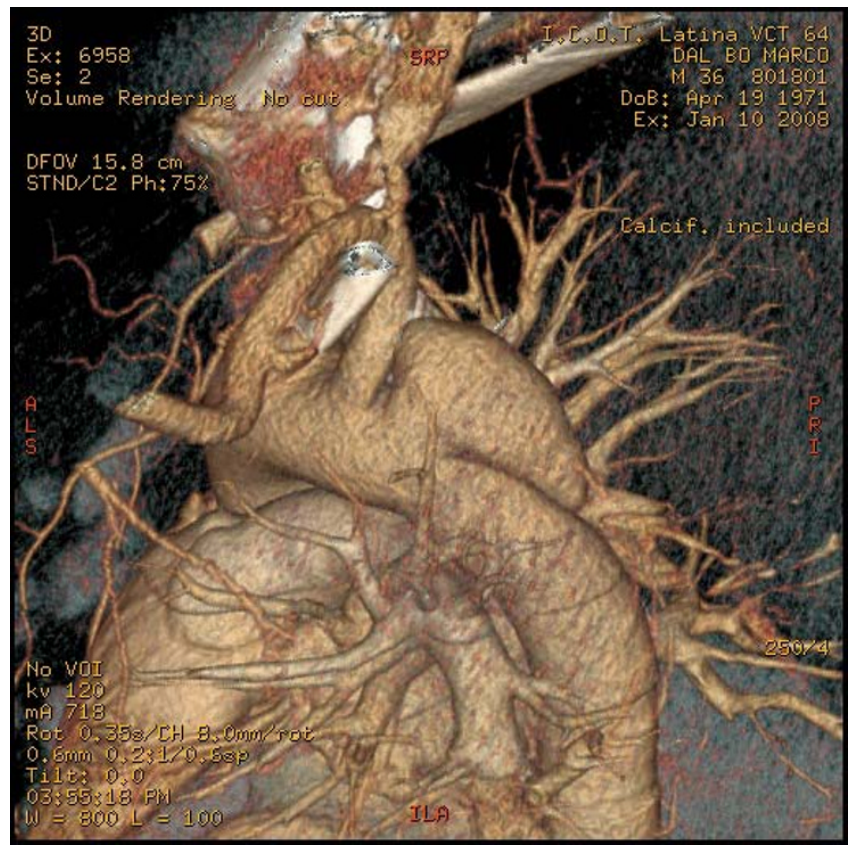

Figure 3

pseudoaneurysm and its relationship with subclavian artery.

the distal arch, as in most of the cases. The patient underwent endograft placement and fully recovered.

\section{References}

I. Bennett $D E$, Cherry JK: The natural history of traumatic aneurysms of the aorta. Surgery 1967, 6I(4):516-523.

2. McCollum CH, Graham JM, Noon GP, DeBakey ME: Chronic traumatic aneurysms of the thoracic aorta: an analysis of $\mathbf{5 0}$ patients. J Trauma 1979, 19(4):248-252.

3. Prat A, Warembourg $\mathrm{H}$ Jr, Watel A, et al: Chronic traumatic aneurysms of the descending thoracic aorta (19 cases). J Cardiovasc Surg (Torino) 1986, 27(3):268-272.

Publish with Bio Med Central and every scientist can read your work free of charge

"BioMed Central will be the most significant development for disseminating the results of biomedical research in our lifetime. " Sir Paul Nurse, Cancer Research UK

Your research papers will be:

- available free of charge to the entire biomedical community

- peer reviewed and published immediately upon acceptance

- cited in PubMed and archived on PubMed Central

- yours - you keep the copyright 